\title{
Thermal Comfort and Optimum Humidity Part 2
}

\author{
M. V. Jokl
}

The hydrothermal microclimate is the main component in indoor comfort. The optimum hydrothermal level can be ensured by suitable changes in the sources of heat and water vapor within the building, changes in the environment (the interior of the building) and in the people exposed to the conditions inside the building. A change in the heat source and the source of water vapor involves improving the heat insulating properties and the air permeability of the peripheral walls and especially of the windows. The change in the environment will bring human bodies into balance with the environment. This can be expressed in terms of an optimum or at least an acceptable globe temperature, an adequate proportion of radiant heat within the total amount of heat from the environment (defined by the difference between air and wall temperature), uniform cooling of the human body by the environment, defined a) by the acceptable temperature difference between head and ankles, b) by acceptable temperature variations during a shift (location unchanged), or during movement from one location to another without a change of clothing. Finally, a moisture balance between man and the environment is necessary (defined by acceptable relative air humidity). A change for human beings means a change of clothes which, of course, is limited by social acceptance in summer and by inconvenient heaviness in winter. The principles of optimum heating and cooling, humidification and dehumidification are presented in this paper.

Hydrothermal comfort in an environment depends on heat and humidity flows (heat and water vapors), occurring in a given space in a building interior and affecting the total state of the human organism.

Keywords: thermal comfort, optimum humidity, hygienic standards.

\section{Hydrothermal microclimate optimization}

An optimum hydrothermal microclimate can be ensured by suitable changes in a) the source of heat, cold and humidity, b) the environment, and c) the exposed subject, the user of the building. An analysis of the current situation by a computer simulation program is a suitable approach to the solution of the problem [4], [18].

\subsection{Changes in the source of heat, cold and humidity}

The most effective method for stabilising indoor conditions is better insulation of outer walls, because the outdoor environment is the greatest source of heat (in summer), cold (in winter) and humidity (all the year). Outer wall insulation improves the thermal insulating properties and also the air tightness [20].

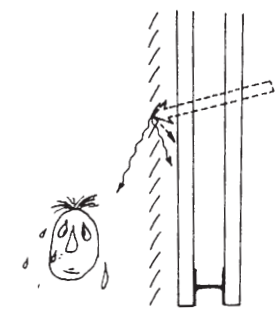

A

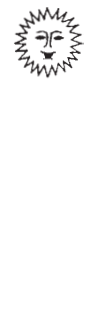

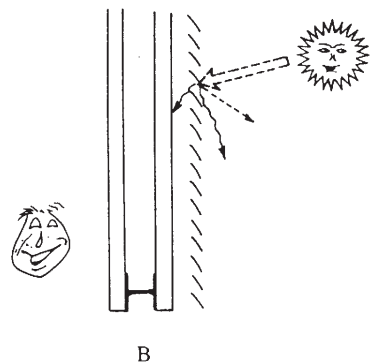

B

\subsubsection{Thermal insulating properties and air permeability of outer walls}

The thermal properties of both walls and windows must be taken into account. Windows, in particular, are usually the source of leaks through which heat escapes in winter and comes in summer - see Part 1, section 2.2. Well insulated windows should be supplemented by outdoor louvres, which prevent excessive solar radiation into an interior in summer, and decrease heat losses in winter. They form an insulating air

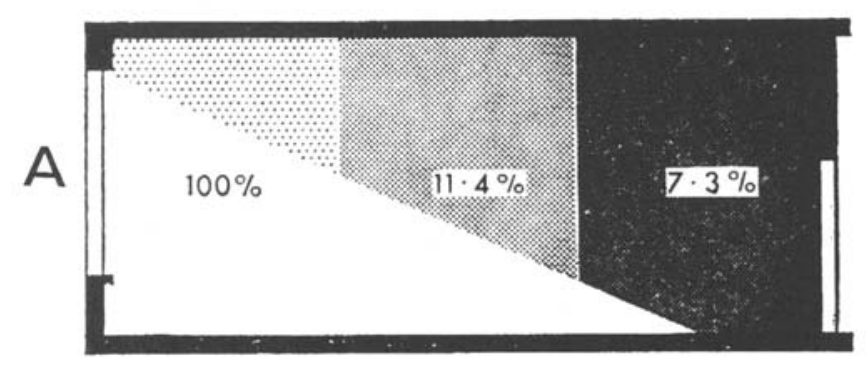

Room without Venetian Blind.

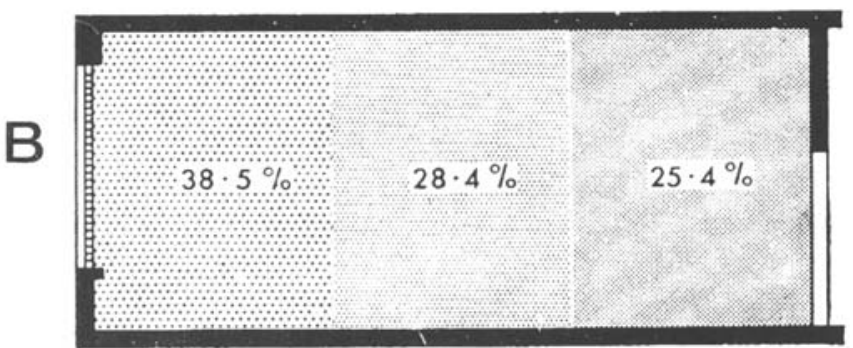

Fig. 2: Impact of the application of horizontal louvres on natural interior illumination (A without louvres, B with louvres) 
layer in front of the window during the night when the losses are greatest, and can reduce energy consumption by as much as $40 \%$ [15] (Fig. 1). Louvres also protect the interior from external noise and can be used to improve indoor lighting (see Fig. 2).

Thermal insulation also plays an important role in indoor air humidity. If it is inadequate, water vapor condensation occurs in low temperature (below dew point) locations. At the same time, windows must allow sufficient ventilation, either by exfiltration, i.e. water vapor delivery to the exterior by windows that are not tights, or by controlled window opening, or by infiltration, i.e. delivery of outdoor air to the interior (see also the section on dehumidification).

\subsection{Changes in the environment}

These changes are more expensive (in terms of capital and running costs). They involve heating and humidification in winter and cooling and dehumidification in summer.

\subsubsection{Optimum heating}

Optimum heating in winter (more exactly during the cold period of the year) (see Table 6 in Part 1) depends on heat losses from a room (heat escaping from indoors to outdoors). Optimum heating provides hydrothermal comfort, i.e.,

a) without drafts,

b) with sufficient heat radiation,

c) with individual control of the heat output.

\section{Heating without drafts}

The provision of heating without drafts depends on the type of heating applied: heating with radiators or warm air heating.

The basic principle for heating with radiators is that the source of heat (the heating body) must be placed close to the source of cold (e.g., the window) in such a way that the impact of cold on the people in the room is eliminated. In practice, this involves placing the radiator under the window, not on an internal wall (Fig. 3). From a heating body on an internal wall the thermal (convective) stream goes up to the ceiling, bends around it and falls down along the outer wall, and is cooled by the window. Thus it changes into a cold draft that cannot be avoided by sealing the window. Placing the heating body under the window changes this situation dramatically: the air cooled by the window drops onto the heating body, is warmed up and changes into a warm thermal stream rising upwards toward the ceiling. From the ceiling it creeps along the internal wall and floor, and a cold draft is avoided. Of course, the heating body must extend along the width of the window. If the floor or ceiling is used as a heating body (with built-in heating pipes) the heating output must be increased considerably near the window (e.g., by increasing the density of the heating pipes). Despite this provision a cold draft often occurs. That is the main problem of this type of heating in apartments and offices.

For warm air heating, the above pattern of air streams within a room is the best way to prevent the formation of a cold draft. The basic principle for warm air heating is that warm air must be released from above and must then go down, i.e., it must be supplied to the ceiling of a room. Otherwise the warm air from the floor goes up and the stream is
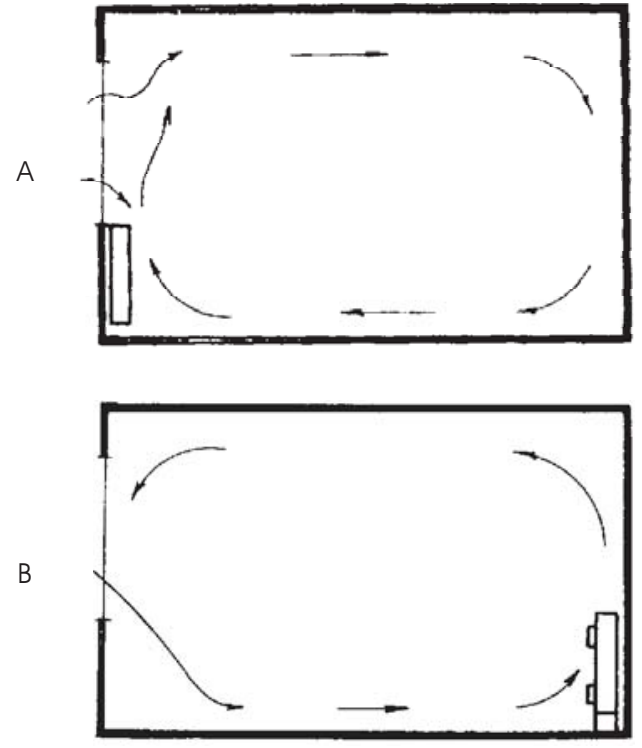

Fig. 3: The impact of the location of a heating body on draft formation (A location without draft, B draft is coming from the window)

typically constricted followed by cold air coming into the room (Fig. 4).

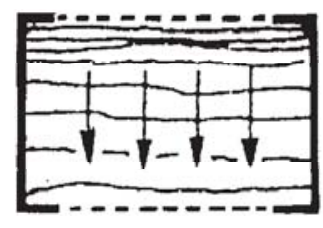

A

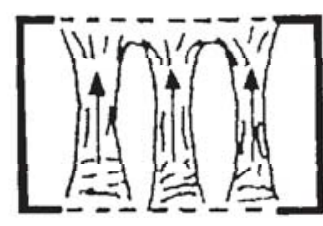

B
Fig. 4: Warm air inlet location for room heating (A correct, B incorrect, because the rising warm air streams are constricted)

\section{Heating with sufficient heat radiation}

Optimum heating also involves providing an adequate portion of radiant heat, i.e., the Radiant Comfort Coefficient must be at least one. This condition is fulfilled draft-free by respecting the basic principle of draft-free heating by radiators, i.e., locating them next to the source of cold. It is different to fulfill the optimum condition of RCC with warm air heating, if convection heaters are not applied. Thus the application of additional radiating sources is recommended with warm air heating, e.g., by installing an open fireplace in a living room.

\section{Heating with individual control}

Individual control means the ability to control the heating system in a room according to the individual requirements of the room user. For example, owing to their lower metabolic rate (heat production) women need a higher room temperature, while people suffering from high blood pressure require a lower room temperature. Thermostatic valves enable the required temperature to be set and automatically maintained.

Personal control is a new type of individual control which maintains the required temperature in a given location in the 
room, e.g., in a working place. This can be done in two ways: by placing the heating body directly in the required location (mostly by using a remotely controlled airconditioning unit) or by placing personally controlled warm air heating inlets in this area.

\subsubsection{Optimum air humidification}

To prevent low air humidity, overheating of the room must be avoided: decreasing the air temperature into the optimum range is often sufficient to achieve the lower relative air humidity limit of $30 \%$.

If it is necessary to achieve the optimum value (e.g., for children allergic to dry air), air humidification must be applied. Special instruments, known as humidifiers, are used. Humidifiers produced by a reputable company should be preferred, because some instruments produce microbes together with water vapor. That is what may happen when a saucer with water is placed on a heating body - and, in addition, a saucer does not usually provide enough water for air conditioning in the room [22].

\subsubsection{Optimum cooling}

Optimum cooling (usually a part of air conditioning) in summer (more exactly during the warm period of the year) (see Table 6 in Part1) depends on neutralising the heat gains in a room (neutralising the heat coming from outdoors to indoors) to provide hydrothermal comfort of the environment, i.e., cooling

a) without drafts,

b) with individual control of the cooling output.

If possible, a ventilation system is preferred for cooling by applying so-called hybrid ventilation. The radiant heat portion causes no problem in summer, RCC being automatically respected in almost all cases.

\section{Cooling without drafts}

The provision of cooling without drafts depends on the type of cooling applied: cooling by air conditioning (packaged) units, cooling by a cooled ceiling, or cooling by a central air conditioning system.

The basic principle for cooling by air conditioning units is that the units must be placed close to the source of warmth (e.g., a window) in such a way that the impact of warmth on the human body is eliminated. This means, in practice, placing the unit under the window (above, to the side, but close to the window) in such a way that the heat radiated from the window on to people is compensated by the cold stream falling on the radiated surface of the body. An air conditioning unit blowing cold air on to a non-radiated body surface as a result of its unsuitable location can even increase the discomfort, because it increases the difference in the heat load on the body between the irradiated and non-radiated sides.

If the ceiling is used as a cooling body, warm air coming from the window near the ceiling is gradually cooled and then falls. This is more favourable than a central air conditioning system, because the air quality is not decreased (e.g., the aeroions are not damaged), no space is necessary for air ducts and machine rooms, and no power is needed for the fans, resulting in energy conservation of about $20 \%$ on comparison with air conditioning.

For cooling by an air handling system, the pattern of air streams within the room is decisive for avoiding draft formation. The basic principle is that cold air must be let in from below and must move upwards, i.e., it must be supplied to the floor of a room. Otherwise, the cold air from the ceiling drops, and the stream is constricted, followed by warm air coming into the room (Fig. 5).

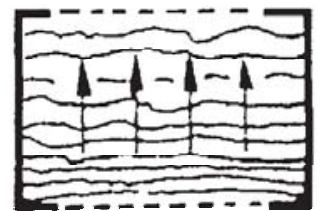

A

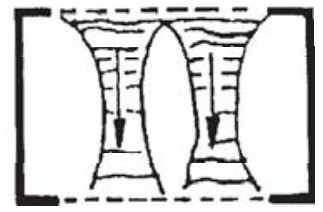

B
Fig. 5: Cold air inlet location for room cooling (A correct, B incorrect, because the falling cold air streams are constricted)

\section{Cooling with individual control}

Individual control means being able to control the cooling system in a room according to the individual requirements of the room user (see also the section on Heating with Individual Control). The required temperature is set and kept automatically, e.g., on a thermostatic valve located on the cooling water pipe before entering the ceiling as a cooling body.

Personal control is a new type of individual control which maintains the required temperature in a given location in a room, e.g. in a working place. This can be done in two ways: by placing a remotely controlled air conditioning unit directly in the required location, or by placing the inlets of the personally controlled central air conditioning system in this area. The operation of the unit can often be programmed, i.e., the required temperature can be changed during the day or week.

\section{Cooling by hybrid ventilation}

Hybrid ventilation is a combination of natural and mechanical ventilation which uses the advantages of both systems. During low outdoor temperatures (up to $+7{ }^{\circ} \mathrm{C}$ without wind) it works as a quiet natural ventilation system, white during warm weather the fan automatically goes into operation, enabling full efficiency of the system [23] (Fig. 6). Hybrid ventilation can also be used for storing cold air in a warm period of the year: if it is in operation all night, the interior of the building is cooled by the cold night air. Thus in the morning and for a part of the day the rooms are pleasantly cool. To achieve successful cooling glazing of the facade should be reduced at least to $40 \%$, outdoor louvres should be installed, and the air should be changed about six times per hour at night.

\subsubsection{Optimum air dehumidification}

The special devices (known as dehumidifiers) are applied to exclude humidity (e.g., for air conditioning of valuable works of art) [19], but in most cases ventilation is sufficient, i.e. the necessary air change within an interior. It is particularly important ventilate bathrooms and kitchens in apart- 


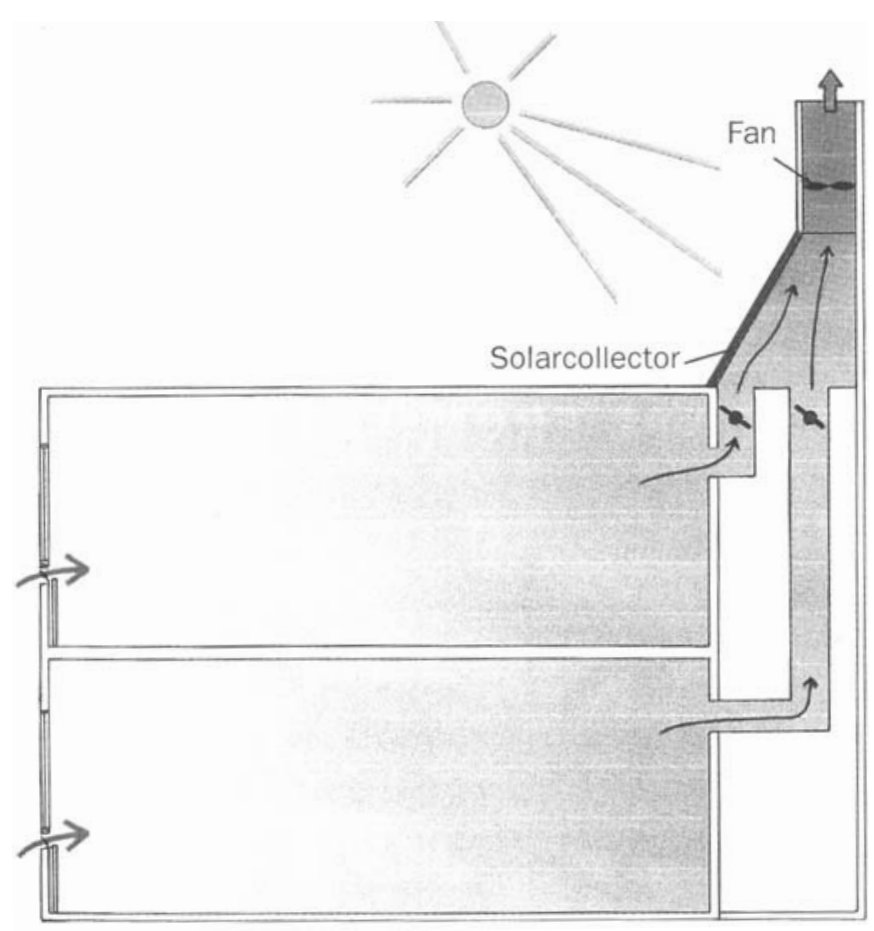

Fig. 6: The principle of hybrid ventilation. It works either naturally - during a cold period, or mechanically - by operating a fan during a warm period to accumulate coolness at night. A solar collector can be applied to increase the chimney effect.

ments (see Table 2 in Part 1). Automatic ventilation devices are controlled by a humidity sensor, which maintains the required air humidity level within a building interior. Placing an exhaust hood above the cooker seems to be the best solution for kitchens. An exhaust hood with filtered air recirculation is sufficient for electrical cookers, while gas cookers need air outlets to the exterior, due to the quantity water vapor that is produced: water vapor from the burnt gas is added to the steam from cooking. An air output of $180 \mathrm{~m}^{3} / \mathrm{h}$ used to be recommended; this has now been increased at least twofold: 360 up to $400 \mathrm{~m}^{3} / \mathrm{h}$ or even $600 \mathrm{~m}^{3} / \mathrm{h}$.

\section{Optimum ventilation}

Unlike the other optimization systems mentioned before, ventilation must be provided all year. Even in winter, when

Table 1: Air quantity and air change during window opening

\begin{tabular}{|c|c|c|c|}
\hline $\begin{array}{c}\text { Window type } \\
(\text { size } 1 \times 1.2 \mathrm{~m})\end{array}$ & $\begin{array}{c}\text { Window } \\
\text { opening }\end{array}$ & $\begin{array}{c}\text { Air quantity } \\
\mathrm{m}^{3} / \mathrm{h}\end{array}$ & $\begin{array}{c}\text { Air change } \\
\text { per hour* }\end{array}$ \\
\hline Hung window & gap $2 \mathrm{~cm}$ & to 50 & 0.25 \\
\hline Hung window & gap $6 \mathrm{~cm}$ & to 130 & 0.65 \\
\hline Hung window & gap $12 \mathrm{~cm}$ & to 220 & 1.1 \\
\hline Swing window & gap $6 \mathrm{~cm}$ & to 180 & 0.9 \\
\hline Swing window & gap $12 \mathrm{~cm}$ & to 280 & 1.4 \\
\hline Swing window & opening $90^{\circ}$ & to 800 & 4.0 \\
\hline \multicolumn{2}{|l|}{$\begin{array}{l}\text { Opposite windows fully } \\
\text { opened (cross ventilation) }\end{array}$} & to 40 & \\
\hline
\end{tabular}

* for $80 \mathrm{~m}^{2}$ floor area there is normally a low quantity of water vapor indoors, ventilation is necessary owing to intensive water vapor production during cooking, taking a shower, etc. [1], [2].

Air quantities and air changes during window opening are presented in Table 1 [21].

The basic principle for optimum ventilation is to ventilate briefly but intensively. Long-time ventilation causes the interior to warm up in summer and cool down up in winter, so it cannot be recommended for reasons of increased energy consumption. Morning ventilation of all rooms, lasting about to 30 minutes (in freezing winter weather only two minutes, in summer time longer, depending on the outdoor temperature). The heating bodies or cooling units must be turned off (for about 30 minutes) before ventilation, especially if thermostatic valves have been installed (when a window is open, the heating or cooling water flow rises to its maximum level). Ventilation (10 to 15 minutes) is recommended three or four times a day, with the window fully open (Fig. 7).

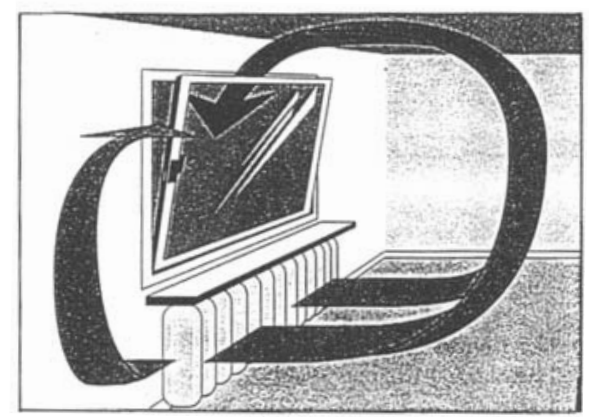

Fig. 7: Ventilation should be brief and intensive

If an air handling system has been installed, there is no need for ventilation by windows. Heat recovery is recommended: it uses the outcoming air to warm up the incoming air in winter and to cool it down in summer. In such a way about $50 \%$ of the heat can be saved. However, some recovery systems reduce the indoor air quality.

\subsection{Human Changes}

The simpliest way to achieve comfort is simply by changing the heat insulating properties of people clothing, i.e., by putting on or taking off the appropriate amount of clothing. However, the possibilities are limited because clothing cannot be decreased below the level accepted from a social point of view in summer, and too heavy clothing can detract from personal comfort in winter.

This situation can be dramatically changed by the results of NASA space research. There is a new high-technology insulation layer consisting of small globes of a manmade material that are smaller than pin-heads. They are filled with paraffines mixtures of hydrocarbons. The phase of the paraffines changes into a solid or a liquid state, depending on the temperature. When they absorb heat, the paraffines melt (like a melting piece of ice), and when emanating heat they solidify. The temperature of the phase change can be set by the composition of the paraffine in the range from $0{ }^{\circ} \mathrm{C}$ up to $132{ }^{\circ} \mathrm{C}$, i.e., a special layer can be designed for every purpose. Two American companies have already started to put this technology application into everday use. Frisby Technologies 
puts these small globes into a foam envelope, while Outlast Technologies have given them a textile cover. The resulting capsules must be designed in such a way that for all possible circumstances they remain paraffineproof. The first area of commercial application is for winter sportswear, especially gloves for snowboarders. The paraffine mixture is chosen in such a way that it is melted by the body temperature and solidifies at $0{ }^{\circ} \mathrm{C}$. The hands produce heat during the sporting activity, and the capsule content slowly liquefies, and heat gradually accumulates. White going uphill on a drag lift the capsule content is slowly cooled, liquefies, and thus solidified with heat emanation to the skin, and the gloves heat the hands. Before the capsule content solidifies even a long uphill ride can be completed. Going down the hill, the capsule content is heated again by the body heat that is produced, and it melts. Then the cycle begins again.

The Van De Sport Company in Tettnagen, in Bavaria offered some special leisure wear, the winter collection of Outlast Technologies, at the International Fair of Sporting Goods in Munich. The Company makes equipment for snowboarders, skiers and mountain climbers. Despite the high prices (ski sportswear costing between 330 to 360 EUR) the company was satisfied with its sales.

Frisby Technologies in Colorado has introduced some new applications: a special foam cover for vertical take-off airplane surfaces, turbine blade protection using microcapsules against high temperatures, so that expensive thermally stable alloying is not necessary, etc. This new technology clearly has great potential.

\section{References}

[1] Centnerová, L.: Ventilation of a family house. Topenářství, instalace, No. 3/1999, pp. 64-65

[2] Chlum, M., Jokl, M., Papež, K.: Progressive ways of residential ventilation. Společnost pro techniku prostředí, Praha 1999, pp. 75

[3] Gullev, G.: Allergy and indoor air climate. SCANVAC 1999, No. 1/1999, pp. 8-9

[4] Hensen, J., Kabele, K.: Application of system simulation to WCH boiler selection. In: Proceedings of $5^{\text {th }}$ Int. IB PSA Conference, Prague 1997, pp. 141-147

[5] Jirák, Z., Jokl, M. V., Bajgar, P.: Long-term and short-term tolerable work-time in a hot environment: the limit values verification. Int. J. of Environmental Health Research No. 7/1997, pp. 33-46

[6] Jokl, M. V.: Microenvironment: The Theory and Practice of Indoor Climate. Thomas, Illinois, U.S.A. 1989, p. 416

[7] Jokl, M. V.: The stereothermometer: A new instrument for Hydrothermal constituent nonuniformity evaluation. ASHRAE Transactions 96, No. 3435/1990, pp. 13-15

[8] Jokl, M. V.: Stereothermometer for the evaluation of a hydrothermal microclimate within buildings. Heizung/Luftung, Klima, Haustechnik 42, No. 1/1991, pp. 27-32
[9] Jokl, M. V.: Stereothermometer an instrument for assessing the non-uniformity of the environmental hydrothermal constituent. Čs. hygiena 36, No. 1/1991, pp. 14-24

[10] Jokl, M. V.: Some new trends in power conservation by thermal insulating properties of buildings. Acta Polytechnica, No. 8/1990, pp. 49-63

[11] Jokl, M. V.: Hydrothermal microclimate: A new system for evaluation of non-uniformity. Building Serv. Eng. Technol. 13, No. 4/1992, pp. 225-230

[12] Jokl, M. V.: Theory of the non-uniformity of the environment at hydrothermal constituent. Stavební obzor 1, No. 4/1992, pp. 16-19

[13] Jokl, M. V.: Internal Microclimate. Czech Technical University in Prague, Prague 1992, p. 182

[14] Jokl, M. V.: The Theory of the Indoor Environment of a Building. Czech Technical University in Prague, Prague 1993, p. 261

[15] Jokl, M. V.: Energetics of Building Environsystems. Czech Technical University in Prague, Prague 1993, p. 148

[16] Jokl, M. V., Moos, P.: Optimal globe temperature respecting human thermoregulatory range. ASHRAE Transactions 95, No. 3288/1989, pp. 329-335

[17] Jokl, M. V., Moos, P.: The nonlinear solution of the thermal interaction of the human body with its environment. Technical Papers, TU Prague, Building Construction Series, PS No. 6/1992, pp. 15-24

[18] Kabele, K., Kadlecová, M., Matoušovic, T., Centnerová, L.: Application of complex energy simulation in competition design of the Czech embassy in Ottawa. In: Proceedings of $6^{\text {th }}$ Int. IBPSA Conference, Kyoto, Japan 1999, pp. 249-255

[19] Kadlecová, M.: Internal microclimate in museums, galeries and exhibition rooms. Dissertation, Czech Technical University in Prague, Prague 1992, pp. 47

[20] Kopřiva, M.: Buildings saving energy. Topenářství, instalace 33, No. 5/1999, pp. 98-99

[21] LUNOS Luftungsfibel. Berlin 1999, pp. 21

[21] Papež, K.: Ventilation and Air Conditioning - exercises. Czech Technical University in Prague, Prague 1993, pp. 116

[22] Sandberg, M.: Hybrid ventilation, new word, new approach. Swedish Building Research, No. 4/1999, pp. 2-3

\footnotetext{
phone: +420224354432

fax: +420233339961

e-mail: miloslav.jokl@fsv.cvut.cz

Czech Technical University in Prague

Faculty of Civil Engineering

Thákurova 7

16629 Prague 6, Czech Republic
}

Miloslav V. Jokl, Ph.D., Sc.D, University Professor 